\title{
Modelling and Analysis of Photovoltaic System under Partially Shaded Conditions using Improved Harmony Search Algorithm
}

\author{
S. Sani*, G. A. Olarinoye, P. U. Okorie \\ Electrical Engineering Department, Faculty of Engineering, Ahmadu Bello University Zaria.
}

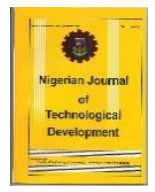

\begin{abstract}
With the increasing penetration of solar electricity in residential, institutional and commercial centres around the globe, the phenomenon of partial shading (PS) in Photovoltaic (PV) power generation is gaining attention. Under Partial shading condition (PSC), cells that are shaded tends to have an equivalent current with cells that are unshaded in series-connection, due to this, the shaded cells operates in reverse bias and consequently becomes load and consumes the generated power. This causes a serious problem known as hotspot. This is characterized by the presence of excessive heat which consequently reduces the total generated power. Recently, researchers use the technique of bypass diodes across the PV cells so that the problem of partial shading can be reduced, but this solution taken alone, has made the nonlinearity and complexity of the system to increase. The shaded cells generate multiple peaks with only one global peak. Conventional Maximum Power Point Tracking (MPPT) algorithms do not differentiates the global peak from local peaks which may end up tracking local peak as global peak, this results in serious power loss. This paper seeks to solve this problem by modelling a PV system under PSC and through the application of Improved Harmony Search algorithm (IHSA) and variable step Perturb \& Observe (P\&O) to track the global peak instead of local peaks. Simulation was done in MATLAB/Simulink 2018a environment, and the results under standard test condition (STC) and PSC showed that the proposed IHSA had an improvement of 25\%, 3.17\% and $2.27 \%, 3.07 \%$ and $2.21 \%, 3.26 \%$ and $2.26 \%$ when compared with the improved particle swarm optimization (IPSO) under STC and PSC conditions respectively, which had a better advantage of minimizing power oscillation and improving the efficiency of the system, improved MPPT tracking, reduced error and a better tracking efficiency in both conditions.
\end{abstract}

KEYWORDS: MPPT, photovoltaic system, partial shading, tracking efficiency, Harmony search algorithm.

\section{INTRODUCTION}

The interests of many researchers are getting attracted towards renewable energy resources. This is due to increasing energy demand and factors that affect the environmental concerns like global warming and some renewable energy sources such as solar energy, biomass, hydro, wind. Among them, solar energy is particularly clean, reliable and easy to harness (Dolara et al.,, 2018). Despite high cost of the solar module, solar energy system is still preferred due to its minimal cost of maintenance, minimal or no pollution $\left(\mathrm{CO}_{2}\right)$, absence of moving parts and long life cycle (Mao et al., 2018; Mao et al.,, 2019). Different algorithms, modelling and control techniques, have been employed in different literatures. Previous research works proposed modifiedalgorithms and artificial intelligence approaches for MPPT control, to differentiate the global peak from local peaks then track the Global Maximum Power Point (GMPP) efficiently under PSC. Other control techniques include; Perturb and Observe (P\&O) (Ahmed \& Salam, 2018), neural networks *Corresponding author: sanisaidudandaura@gmail.com and fuzzy logic (Koad et al.,, 2016). Under PSC, the PV characteristic curve is characterized by the presence of nonlinear and multi-peak characteristics of which only one corresponds to the global peak. Hill Climbing techniques usually regarded as conventional MPPT techniques, which include $\mathrm{P} \& \mathrm{O}$ amongst others can not differentiate global peak from local peaks which results in tracking a local peak. Consequently, the system experiences power oscillations and reductions in efficiency. To mitigate this problem, many researchers have proposed modified algorithms for MPPT control under PSC to track the GMPP.

In Shams El-Dein (2012), effort was made in reducing partial shading (PS) losses by reconfiguration; the author formulates the reconfiguration problem as a mixed integer quadratic programming problem and made use of the branch and bound algorithm to obtain the GMPP. This method requires large number of switches, this make the system very complex, with high cost of hardware implementation. Ant colony optimization (ACO) based MPPT control scheme was doi: http://dx.doi.org/10.4314/njtd.v17i4.4 
proposed by (Jiang et al.,, 2013). Results of the simulations indicated the performance effectiveness of the control technique. Unfortunately, this approach was limited by a slow convergence speed. A technique with fuzzy logic for weather dependency adaptation was proposed in (Valdez et al., 2014). Fuzzy logic was applied to dynamically adapt to key parameters which yielded an improved results than the conventional methods. This technique coverged slowly with some power oscillation.

A combined PSO \& P\&O-based MPPT system was proposed in (Lian et al.,, 2014). PSO was used to search for the GMPP. P\&O method was applied to track the GMPP. This method has fast searching capability while it suffers from power oscillation problem around the maximum power point (MPP), this causes considerable power loss. In Duan et al., (2015), the authors used P\&O based on improved variable steps method to scan the PV curves and track the GMPP. The time taken to scan the curves makes the system take longer time to converge. Wei et al., (2017) proposed an improved PSO-based MPPT scheme. An analysis of the I-V and P-V characteristic curves was performed. The closest point to the MPP was set as the initial position of the particles and the fitness value was determined by real-time sampling of output power and not by iterations. This method succeeds in improving the convergence speed by cutting out the problem of repeated iterations as in traditional PSO.

However, the proposed method did not give satisfactory result due to the presence of power oscillation around the MPP. An improved Particle Swarm Optimization (IPSO)based technique combined with Variable step P\&O was proposed in (Yang et al.,, 2017). The IPSO was formed by mapping the grouping idea of shuffle frog into conventional PSO and searched for approximate GMPP. The P\&O based on variable steps is then used to track the GMPP dynamically. The proposed method was found to be effective in mitigating the MPPT problems under PSC. However, computational burden increased and often leads to slow convergence. A Harmony Search Algorithm (HSA)-based MPPT method was proposed in (Keerthi et al., 2017). The HSA provides suitable duty cycle to the Boost converter for MPPT control; this does not depend on the power produced by solar panels. The method performs under uniform and partially shaded conditions but suffers from slow convergence due to fixed value of the HSA parameters, which must be chosen carefully at initialization stage.

Lopez-Santos et al., (2018) proposed an MPPT method based on power versus Static Conductance (P-G) curve obtained by linear approximation of I-V curve. The authors employed P-G curve of the PV array to accurately track the maximum power. However, the I-V curve could not guarantee accuracy due to its approximation. This technique requires scanning of the $\mathrm{P}-\mathrm{V}$ curve thereby giving rise to slow convergence rate. In Pilakkat and Kanthalakshmi (2019), an artificial bee colony-perturbs and observe (ABC-PO) algorithm was proposed. The tracking ability of $\mathrm{P} \& \mathrm{O}$ was combined with the searching ability of the $\mathrm{ABC}$ to produce an MPPT scheme. ABC was employed to search for the GMPP while P\&O was employed track the GMPP. The proposed technique was found to be efficient in tracking the
GMPP but suffers from slow convergence speed due to increased complexity of the system. This paper seeks to develop a global peak MPPT scheme for PV system under PSC using improved harmony search algorithm (IHSA) combined with variable steps $\mathrm{P} \& \mathrm{O}$ for the purpose of fast convergence time and reduced steady state power oscillation.

The paper is organized as follows, section I discusses the introduction, while in section II, the PV cell was modelled. Section III succinctly elaborated the MPPT proposed algorithm alongside the harmony search algorithm (HSA) with the improved HSA, section IV introduced the objective function, while section $\mathrm{V}$ presents the results and discussion, and the conclusion is drawn finally in section VI.

\section{MODELLING THE PV CELL}

The PV cell is the essential unit of the PV system and it is essential for MPPT control system in PV system. PV cells can be modelled as in Figure 1.

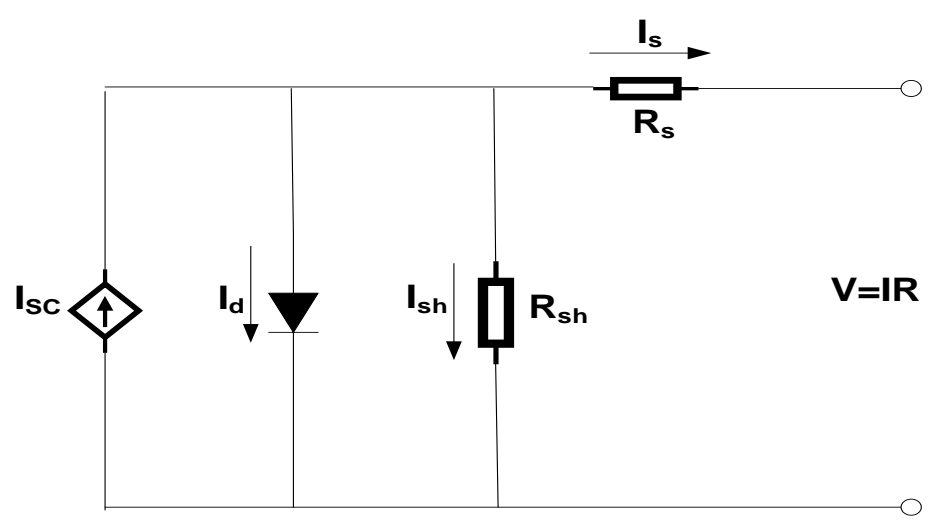

Figure 1: PV cell model based on single diode.

By applying Kirchhoff's current law (KCL) to Figure 1, the output of the current is given as follows (Ovaska, 2010; Saidu et al.,, 2019; Yang et al.,, 2017);

$$
\begin{aligned}
& I=I_{s c}-I_{d}-I_{s h} \\
& I_{s h}=\frac{V+I R_{s}}{R_{s h}} \\
& I_{d}=I_{0}\left(e^{\frac{\left(V+I R_{s}\right)}{\alpha V_{T}}}-1\right) \\
& I=I_{s c}-I_{o}\left(e^{\frac{\left(V+I R_{s}\right)}{\alpha V_{T}}}-1\right)-\frac{V+I R_{s}}{R_{s h}}
\end{aligned}
$$

where:

$I_{s c}$ : Photocurrent produced by the incidence of light (A)

$I_{d}:$ Current of the diode (A)

$I_{o}:$ Reverse Saturation Current of the diode (A)

$R_{s}$ : Series Resistance $(\Omega)$

$R_{\text {sh }}:$ Shunt Resistance $(\Omega)$

$V$ : Output Voltage of the PV cell

$A$ : Diode Ideality Factor

$T$ : Absolute Temperature in Kelvin (K) 
$q$ : Electron Charge $\left(1.60217646 \times 10^{-23} \mathrm{~J} / \mathrm{K}\right)$

Equation (4) represent theoretical model of the PV cell. However, in practice, parameters of the PV cell model are difficult to obtain without making some assumptions (Ahmad et al.,, 2020). The practical model of the PV cell is thus obtained by making the following assumptions (Saidu et al.,, 2019).

i. $\quad \frac{V+I R_{s}}{R_{s h}}$ is negligible

ii. Under open circuit condition, $I=0$ and $V=V_{o c}$

iii. At the maximum power point (MPP) $V=V_{m}$ and $I=I_{m}$

This practical model considers the following; the open circuit voltage, maximum power for optimal energy derivation and short circuit current. It equations are given as follows (Yang et al.,, 2017):

$$
I=I_{s c}\left(1-C_{1}\left\{\exp \left[\frac{V}{C_{2} V_{o c}}\right]-1\right\}\right)
$$

Where (Saidu et al.,, 2019):

$$
\begin{aligned}
& C_{1}=\left(1-\frac{I_{m}}{I_{s c}}\right) \exp \left[\frac{-V}{C_{2} V_{o c}}\right] \\
& C_{2}=\left(\frac{V_{m}}{V_{o c}}-1\right)\left[\ln \left(1-\frac{I_{m}}{I_{s c}}\right)\right]
\end{aligned}
$$

Where $C_{1}$ and $C_{2}$ are the input and output capacitances respectively.The power of the PV array is calculated as in equation (8) (Saidu et al.,, 2019).

$$
P=n_{p} I_{s c} V-n_{p} V I_{d}\left[\exp \left(\frac{q}{K T A} \frac{V_{o c}}{n_{s}}\right)-1\right]
$$

\section{PROPOSED MPPT ALGORITHM}

The IHSA is discussed in this section as employed to search for the GMPP and variable steps P\&O method that was used as the initial position for the GMPP to track its accuracy.

\section{A. Harmony Search Algorithm (HSA)}

The HSA is a population based meta-heuristic algorithm developed from musical process of searching for better state of harmony, proposed by Geem et al., (2001). The optimization processes of HSA are outlined as follows (Zhao et al.,, 2011):

Step 1: Set the algorithm parameters and initialization of the harmony memory (HM).

$$
H M=\left[\begin{array}{cccc|c}
x_{1}^{1} & x_{2}^{1} & \ldots & x_{D}^{1} & \text { fitness }\left(x^{1}\right) \\
x_{1}^{2} & x_{2}^{2} & \ldots & x_{D}^{2} & \text { fitness }\left(x^{2}\right) \\
\vdots & \vdots & \ldots & \vdots & \vdots \\
x_{1}^{\text {HMS }} & x_{2}^{\text {HMS }} & \ldots & x_{D}^{\text {HMS }} & \text { fitness }\left(x^{\text {HMS }}\right)
\end{array}\right]
$$

where each member of the $\mathrm{HM}\left(x_{1}^{1} \cdots x_{D}^{H M S}\right)$ is a solution candidate with fitness order $\left[\right.$ fitness $\left(x^{1}\right) \cdots$ fitness $\left.\left(x^{H M S}\right)\right]$.

Step 2: Improvisation of New Harmony

This stage involve generating new harmony from the values stored in the HM. Improvise a new harmony from HM using three criteria, namely: memory considerations, pitch adjustments and randomization. Each harmony generated by randomization is tested whether it should be pitch adjusted or not, equation (10) is used during improvisation process (Manjarres et al.,, 2013)

$$
x_{i}=x_{i} \pm \operatorname{rand}(0,1) * b w
$$

where:

$b w$ is an arbitrary bandwidth distance;

$\operatorname{rand}(0,1)$ is a random number ranging from 0 to 1 .

\section{Step 3: Update the HM}

From the order of the objective function, the new solutions are evaluated from step 2. Giving an improved fitness, the worst member in the HM is replaced, otherwise, the HM eliminates it.

Step 4: Check for Termination Criteria

The termination criteria is checked, and the best solution found is returned, otherwise step 2 and 3 are repeated, until maximum number of iterations is met.

\section{B. Improved Harmony Search Algorithm (IHSA)}

IHSA was employed to improve the performance and mitigate the problems of the HSA due to fixed pitch adjustment rate (PAR) and bandwidth $(b w)$ values. The difference between IHSA and traditional HSA is in the improvisation step. IHSA uses variable parameters values, while traditional HSA uses fixed values of PAR and $b w$. The values of PAR dynamically changes as the generation number changes, this is given as follows (Mahdavi et al.,, 2007):

$P A R(g n)=P A R_{\min }+\frac{\left(P A R_{\max }-P A R_{\min }\right)}{N I} \times g n$

where:

$P A R(g m)=$ pitch adjustment rate for each generation number

$P A R_{\min }=$ minimum pitch adjustment rate

$P A R_{\max }=$ maximum pitch adjustment rate

$N I=$ number of solution vector generations

$g n=$ generation number 
The IHSA search for the GMPP and the variable steps P\&O

$b w=$ changes as generation number varies, and is defined in Eq. (12).

$b w(g n)=b w_{\max } \exp (c \cdot g n)$

$c=\frac{\ln \left(\frac{b w_{\max }}{b w_{\min }}\right)}{N I}$

where:

$b w_{\min }$ and $b w_{\max }$ are the minimum and maximum bandwidths. $b w(g n)=$ bandwidth of each generation.

For the performance of the proposed method to be improved, Eq. (14) is introduced to control the ON process of the bypass diodes for switching loss minimization (Mohapatra et al.,, 2017).

$$
V_{2}-\sum_{i=1}^{n} V_{i} \geq V_{D O}, \quad i \neq 2
$$

where:

$V_{D O}$ is the break down voltage of the bypass diodes and $V_{2}$, $V_{i}$ are the input voltages.

\section{Variable Steps Perturb and Observe Algorithm}

The traditional $\mathrm{P} \& \mathrm{O}$ algorithms adopt a fixed step values. Long step causes power oscillation around the GMPP, and small step value lead to slow convergence process (Lian et al.,, 2014). An adaptive variable step $\mathrm{P} \& \mathrm{O}$ overcomes the problem of power oscillation and slow tracking speed. The duty cycle always regulates the MPPT control. It is selected by the algorithm as the disturbance constant. The perturbation and duty cycle can be expressed as (Yang et al.,, 2017).

$$
\Delta D=\alpha \frac{P-P_{\text {old }}}{D-D_{\text {old }}}
$$

where:

$D:$ The duty Cycle

$P$ : Power of the PV module

$\alpha=$ adaptive factor whose value can be estimated as (16).

$$
\alpha \approx \frac{D_{\text {step }}}{|d P / d D|_{\max }}
$$

where:

$D_{\text {step }}=$ initial step length

$|d P / d D|_{\max }=$ the maximum value in the $d P / d D$ curve.

$d P / d D$ is compared with the error and based on the value of the error, a corresponding step is given. Figure 2 shows the flowchart of the IHSA based MPPT for the PV system. set the GMPP value as the initial stage for tracking. Whenever the variation in output power is great due to non-uniform illumination across the PV cells caused by partial shading, the restart will run again for MPPT control. The restart condition is set as follows (Eltamaly \& Abdelaziz, 2020):

$\frac{P_{r e a l}-P_{m}}{P_{p v}}>\Delta P$

where:

$P_{m}=$ recorded power

$\Delta P=$ rate of change of the output power.

Note that $\Delta P$ may be set as $5 \%$ based on the results obtained from the simulation.

\section{Partial Shading Condition (PSC)}

PSC is the situation at which PV array receives non uniform insolation. Insolation and temperature greatly influence the GMPP of a PV array. Due to change in weather condition, irradiance and temperature varies thereby changing the GMPP. This necessitates the need for GMPP tracking. Under PSC, the actual PV array power is less than its value in theory. Partial shading can be detected when equation (18) is satisfied (Yang et al., 2017):

$P_{P V}\left[\frac{G}{G_{S T}}\right]\left[1+\alpha_{p}\left(T-T_{S T C}\right)\right]>P_{\text {real }}$

where:

$P_{\text {real }}=$ Actual output maximum power

$P_{P V}=\mathrm{PV}$ rated power in module

$G=$ Actual solar radiation

$G_{S T}=$ Insolation under standard test conditions $\left(1000 \mathrm{w} / \mathrm{m}^{2}\right)$

$\alpha_{P}=\mathrm{PV}$ module temperature coefficient of power

$T=\mathrm{PV}$ module actual temperature

$T_{S T C}=$ Temperature under standard test condition

\section{IV.OBJECTIVE FUNCTION FOR MPPT CONTROL}

The objective function $f(x)$ is the PV array output power. The formulation is as follows;

$\max$ imize $f(x)=P_{p v}=\left(V_{p v} \times I_{p v}\right)$

Maximization objective: If $f\left(X_{n e w}\right)>f\left(X_{w}\right)$ 


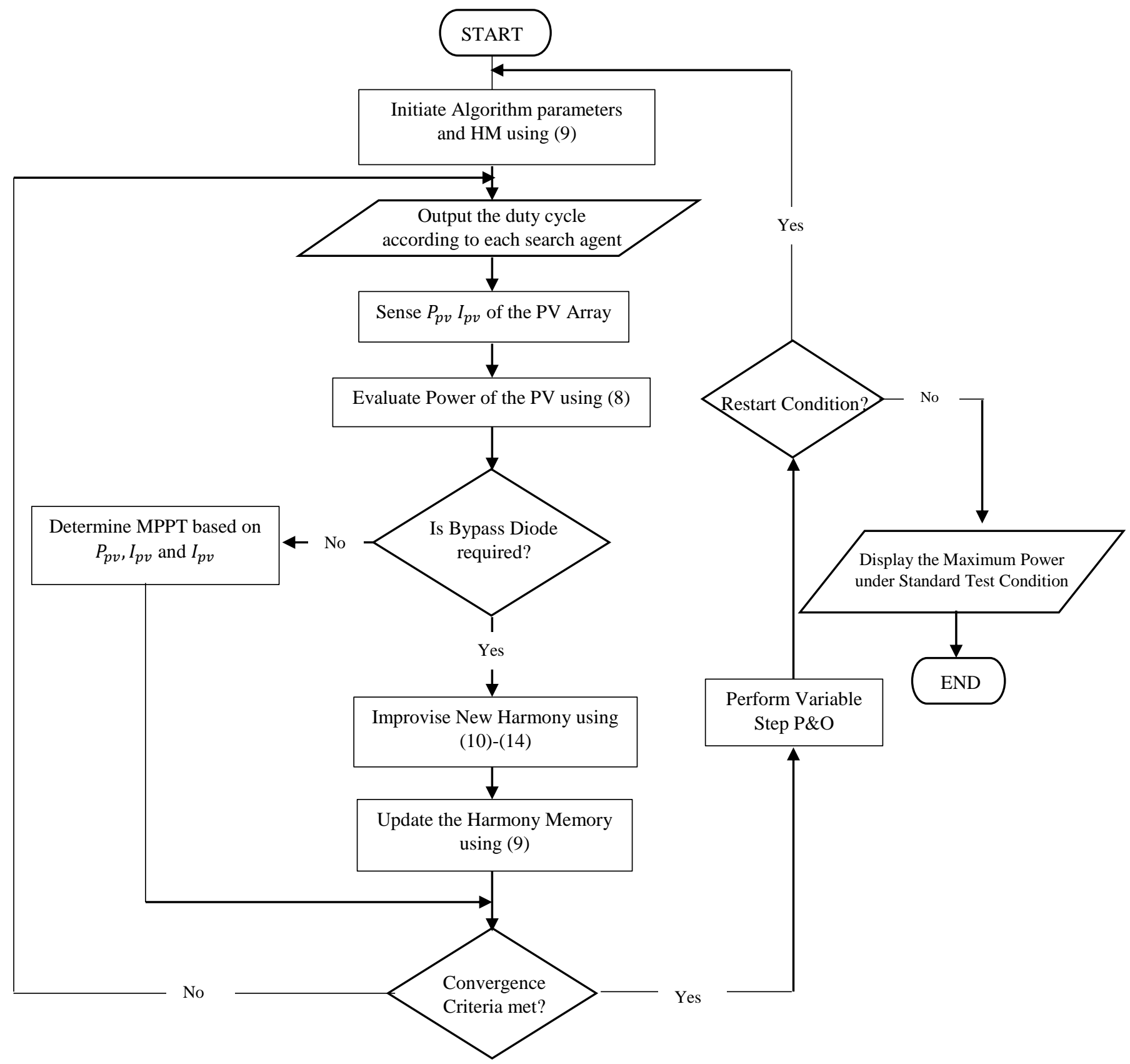

Figure 2: Flowchart of the IHSA based MPPT for the PV System.

Subject to the following constraints:

$$
\begin{gathered}
f(x)=\left(n_{p} I_{s c}-n_{p} V I_{d}\left[\exp \left(\frac{q}{K T A} \frac{V_{o c}}{n_{s}}\right)-1\right]\right) \\
\left\{\begin{array}{l}
\frac{P_{i+1}-P_{i}}{P_{i}} \geq 5 \% \\
V_{i+1}-V_{i} \geq 0.5 \% \\
V_{2}-\sum_{i=1}^{n} V_{i} \geq V_{D O}, i \neq 2
\end{array}\right.
\end{gathered}
$$

where:

$$
\begin{aligned}
& i+1=\text { the current value } \\
& i=\text { the previous value, } \\
& V_{D O}=\text { the break down voltage of the byepass diodes. }
\end{aligned}
$$

The first constraint detects the change in power. The second constraint detects the voltage variation and prevents the algorithm from the diverged tracking direction. The third constraint controls the $\mathrm{ON}$ process of the bypass diodes. When the third constraint is satisfied, the bypass diodes become active. 


\section{SIMULATION RESULTS}

The PV Array model and the buck-boost converter developed in MATLAB/Simulink 2018a environment is provided in Figures 3 and 4 respectively considering two PV array models. The PV array was formed by series connection of two PV panels. Table 1 presents the simulation data of the single PV panel at STC.

Table 2 presents the simulation data of the buck-boost converter as adopetd form Yang et al., (2017). The characteristics curves of $I-V$ and $P-V$ for the PV system were obtained for STC and PSC from the PV array model with the view to analyse these conditions. Figure 5 gives the $I-V$ and the $P-V$ characteristic curves. It can be observed that the $I-V$ curve produce single step whereas the $P-V$ curve produce also a single peak under PS. The $P-V$ characteristic curve produce a single peak under STC.

Table 2: Buck-Boost converter parameters.

\begin{tabular}{lcc}
\hline \multicolumn{1}{c}{ Parameter } & Symbol & Value \\
\hline Inductor & $L$ & $800 \mu \mathrm{H}$ \\
Input Capacitance & $C_{1}$ & $100 \mu \mathrm{F}$ \\
Output Capacitance & $C_{2}$ & $220 \mu \mathrm{F}$ \\
Resistance & $R_{\text {load }}$ & $20 \Omega$ \\
Switching Frequency & $F$ & $20 \mathrm{kHz}$ \\
\hline
\end{tabular}

Table 1: Simulation parameters of single PV panel under STC.

\begin{tabular}{lc}
\hline Parameter & Value \\
\hline Cell Temperature $\left({ }^{o} C\right)$ & 25 \\
Air mass & 1.5 \\
Insolation $\left(W / m^{2}\right)$ & 1000 \\
Open-circuit Voltage $(V)$ & 21.6 \\
Short-circuit Current $(A)$ & 2.25 \\
Peak Power $(W)$ & 35 \\
Maximum Volatage $(V)$ & 17.6 \\
Maximum Current $(A)$ & 1.98 \\
Temperature Coefficient of & 0.038 \\
$I_{s c}\left(\%{ }^{o} C\right)$ & \\
Temperature Coefficient of & -0.3738 \\
$V_{o c}\left(\%{ }^{o} C\right)$ & \\
Number of Seies Connected & 1 \\
Module per String & \\
Number of Parralel String & 1 \\
Light-generated Current $I_{L}(A)$ & 2.2637 \\
Diode Saturation Current $I_{o}(A)$ & $1.148 \mathrm{e}-10$ \\
Diode Ideality Factor & 0.65947 \\
Shunt Resistance $(\Omega)$ & 103.7418 \\
Series Resistance $(\Omega)$ & 0.63239 \\
\hline
\end{tabular}

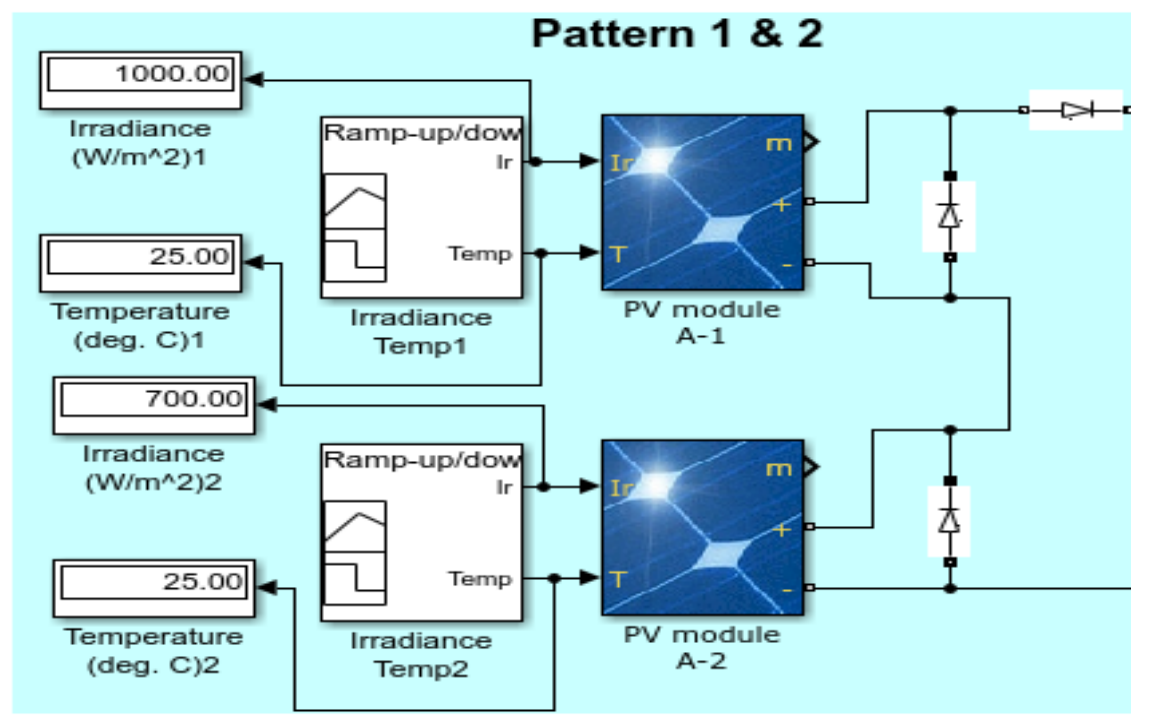

Figure 3: Model of the PV array in MATLAB/Simulink.

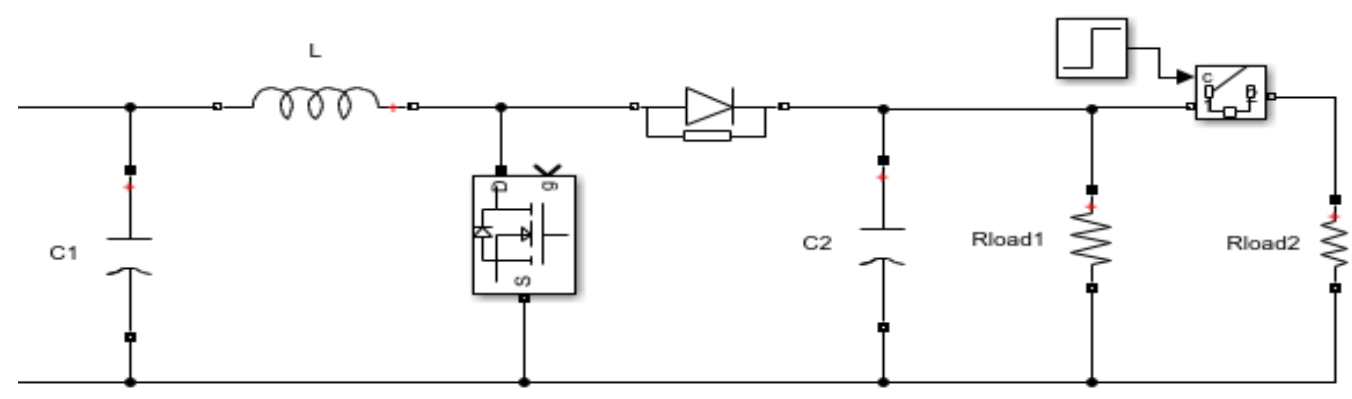

Figure 4: Model of the buck boost converter in MATLAB/Simulink. 

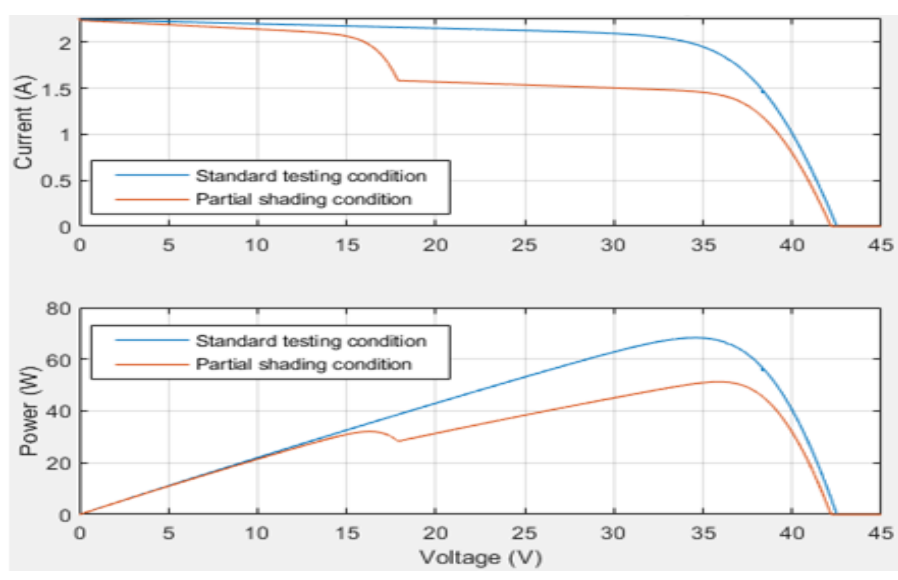

Figure 5: $I-V$ and $P-V$ characteristic curves under STC and PSC.

It was observed that in Figure 5, the maximum power reduces drastically from $70 \mathrm{~W}$ to $52.3 \mathrm{~W}$ due to unequal insolation condition. At this point, the restarting conditions are satisfied and therefore, the proposed method restarts for MPPT control. Under STC, IHSA algorithm was employed to search for the global peak. After 0.06 secs of the searching process, the best harmony was found to be $69.96 \mathrm{~W}$, while the corresponding duty cycle for the best harmony is 0.561 . The relative error is $0.04 \%$ when compared to the theoretical value of $70 \mathrm{~W}$. The tracking efficiency was found to be $99.94 \%$. An IHSA algorithm was employed to provide suitable duty cycle value to the buck-boost converter for MPPT control. Table 3 shows IHSA parameters.

Figure 6 shows the simulation results of the power and duty cycle plots for the IPSO-based method. It can be observed that under STC the IPSO found the best particle to be $67.82 \mathrm{~W}$, while the duty cycle corresponding to the best particle is 0.601 with a relative error of $3.11 \%$ compared to
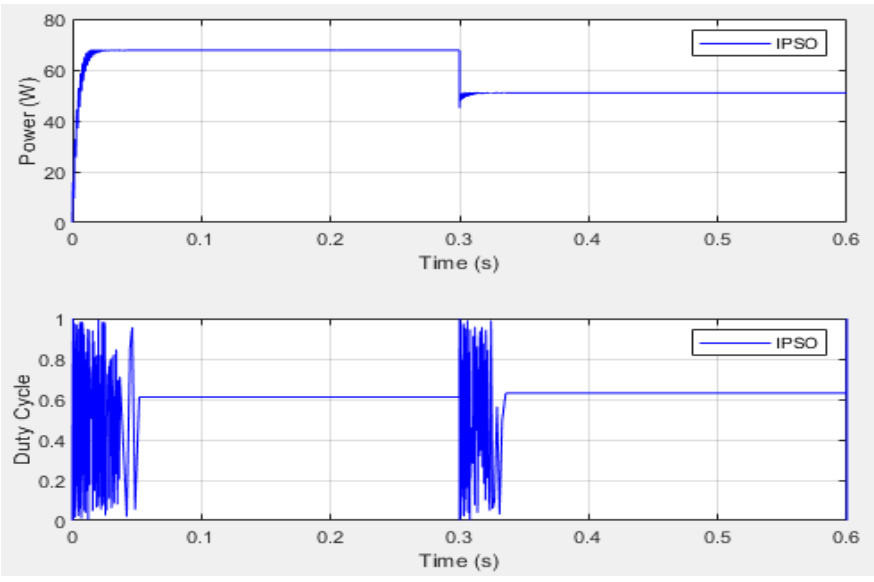

Figure 6: Power and duty cycle for the IPSO-based method.

the theoretical value $70 \mathrm{~W}$, and the tracking efficiency was found to be $96.80 \%$. At $0.3 \mathrm{sec}$ of the simulation process, the insolation drastically stepped down from $1000 \mathrm{~W} / \mathrm{m}^{2}$ to 700 $\mathrm{W} / \mathrm{m}^{2}$. This action satisfied restarting condition and the IPSO algorithm auto restarts. The best particle was found to be
$51.10 \mathrm{~W}$, while the duty cycle corresponding to the best particle is 0.611 with a relative error of $2.29 \%$ compared to the theoretical value of $52.3 \mathrm{~W}$ and tracking efficiency of $97.71 \%$.

The power and duty cycle plots for the IHSA based method is shown in Figure 7. It can be observed that under STC, the IHSA found the best harmony to be $69.97 \mathrm{~W}$ while the duty cycle corresponding to the best harmony was found to be 0.561 with relative error of $0.04 \%$ compared to the theoretical value of $70 \mathrm{~W}$, and the tracking efficiency was found to be $99.96 \%$. At 0.3 secs of the simulation process, the insolation drastically stepped down from $1000 \mathrm{~W} / \mathrm{m}^{2}$ to $700 \mathrm{~W} / \mathrm{m}^{2}$. This action satisfied the restarting condition and the IHSA algorithm auto restarts for MPPT control. The best harmony was found to be $52.26 \mathrm{~W}$ while the duty cycle corresponding to the best harmony is 0.580 with a relative error of $0.08 \%$ compared to the theoretical value of $52.3 \mathrm{~W}$, and tracking efficiency of $99.92 \%$.
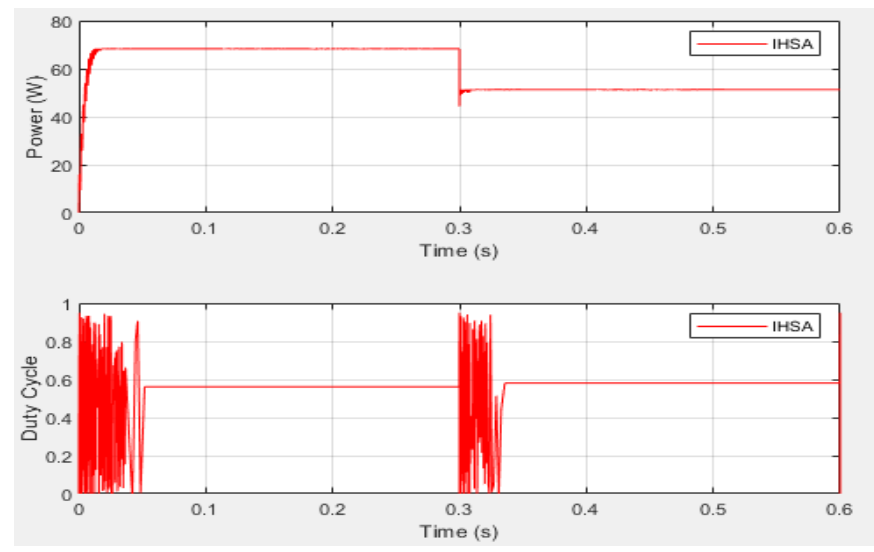

Figure 7: Power and duty cycle for the IHSA-based method.

The P-T simulation result of the IHSA-based method for MPPT control is shown in Figure 8, when compared with a similar result obtained for the IPSO based-method.

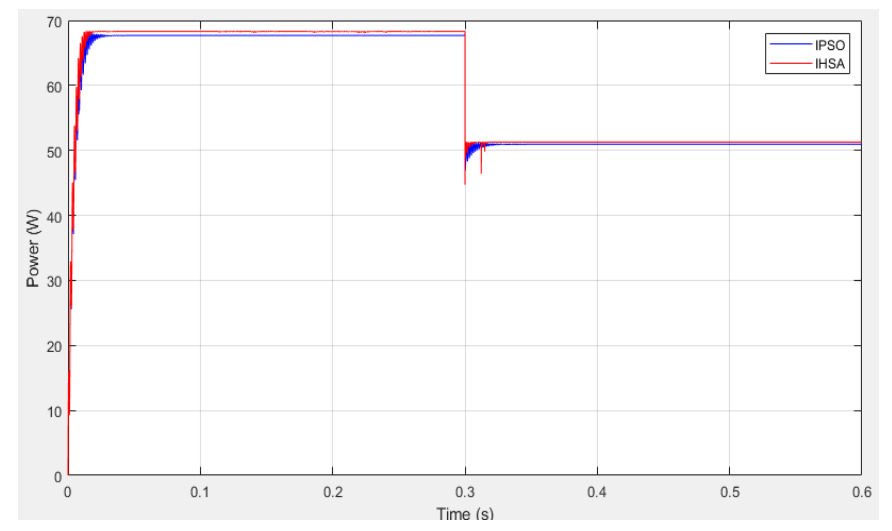

Figure 8: P-T plots comparison between the IPSO and IHSA-based methods.

The IHSA algorithm's searching time is about $0.06 \mathrm{~s}$ which has a short duration than that of the IPSO which is $0.08 \mathrm{sec}$. Also the tracking efficiency of $99.96 \%$ and $99.92 \%$ was obtained using IHSA-based method under STC and PSC respectively, 
this marked 3.26 and $2.26 \%$ improvement compared to 96.80 $\%$ and $97.71 \%$ respectively for the IPSO-based approach.

Figure 9 shows the V-T Plots comparison between the IPSO-based and IHSA-based approach. From the figure, when the irradiance changes, the IHSA adjusts the duty cycle to increase the PV voltage operating point until it reaches the operating point that corresponds to MPP. The adjustment of the duty cycle causes a corresponding increment in open circuit voltage as shown in the figure, with a corresponding decrement in short circuit current as shown in Figure 10 during MPPT control.

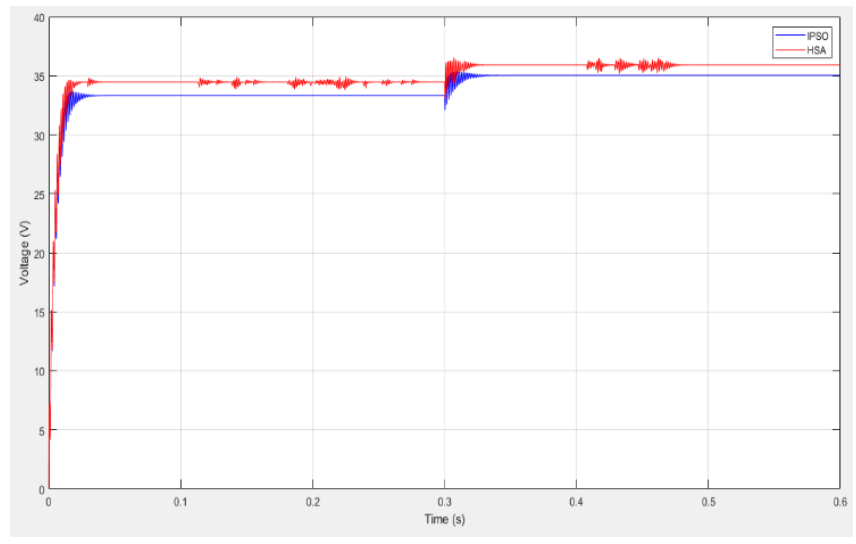

Figure 9: V-T plots comparison between the IPSO and IHSAbased approach.

Figure 10 shows the I-T Plots comparison between the IPSO and IHSA-based approaches. Table 4 presents a summary of the results obtained for both the IHSA-based and the IPSO-based methods.

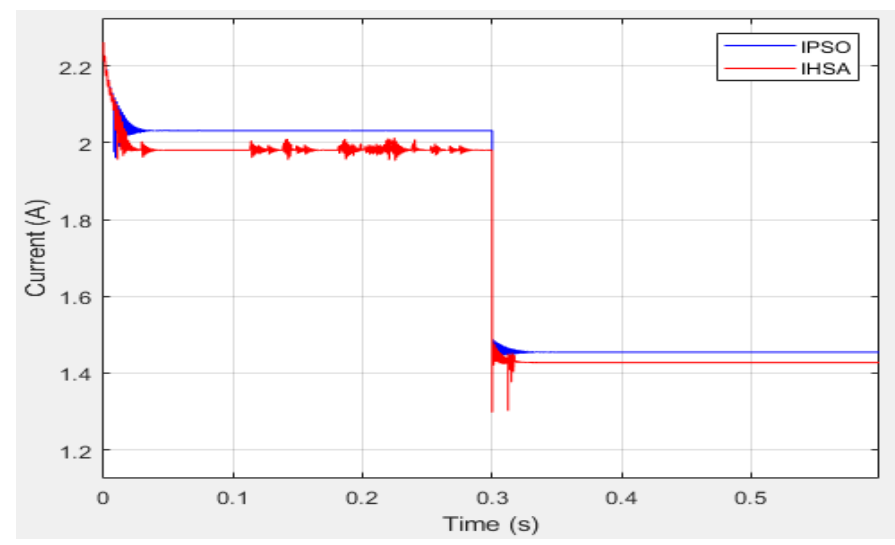

\section{CONCLUSION}

An improved harmony search algorithm (IHSA)-based MPPT scheme for PV system under PSC has been developed. The IHSA was applied to search rapidly for the GMPP, and the variable steps P\&O method was used in setting the GMPP as the initial position to track the accurate GMPP instantaneously. The performance of the proposed IHSAbased method was compared with that of the IPSO-based method using searching time, maximum power point (MPP), relative error and tracking efficiency as the performance metrics. It showed that the IHSA algorithm had an improvement of $25 \%$ in terms of fast searching time which has the advantage of minimizing power oscillation and improving the efficiency of the system under STC and PSC.

Also, it had an improvement of $3.17 \%$ and $2.27 \%$ in terms of maximum power point when compared to IPSO under STC and PSC, a reduced relative error of $3.07 \%$ and $2.21 \%$, and an improved tracking efficiency of $3.26 \%$ and $2.26 \%$ under STC and PSC respectively when compared with the IPSO. Further work will consider taking experimental data and making comparison, and also implementing the scheme in a real life scenario.

\section{REFERENCES}

Ahmad, F. F.; C. Ghenai; A. K. Hamid and M. Bettayeb. (2020). Application of sliding mode control for maximum power point tracking of solar photovoltaic systems: A comprehensive review. Annual Reviews in Control, 49, 173-196. doi:https://doi.org/10.1016/j.arcontrol.2020.04.011

Ahmed, J. and Salam Z. (2018). An Enhanced Adaptive P\&O MPPT for Fast and Efficient Tracking Under Varying Environmental Conditions. IEEE Transactions on Sustainable Energy, 9(3), 1487-1496. doi:10.1109/TSTE.2018.2791968

Dolara, A.; F. Grimaccia; M. Mussetta; E. Ogliari and S. Leva. (2018). An Evolutionary-Based MPPT Algorithm for Photovoltaic Systems Under Dynamic Partial Shading. Applied Sciences, 8(4), 558. doi:https://doi.org/10.3390/app8040558

Duan, Q.; J. Leng; P. Duan; B. Hu and M. Mao. (2015). An improved variable step $P O$ and global scanning MPPT method for PV systems under partial shading condition. Paper presented at the 2015 7th International Conference on Intelligent Human-Machine Systems and Cybernetics, Hangzhou, China.

Eltamaly, A. M. and Abdelaziz, A. Y. (2020). Modern Maximum Power Point Tracking Techniques for

Figure 10: I-T plots comparison between the IPSO and IHSAbased approaches.

Table 4: Summary of the results obtained.

\begin{tabular}{lccc}
\hline Parameters Description & $\begin{array}{c}\text { IPSO-Based Method. } \\
\text { (STC\&PSC) } \\
\text { Respectively }\end{array}$ & $\begin{array}{c}\text { IHSA-Based Method } \\
\text { (STC \& PSC) } \\
\text { Respectively }\end{array}$ & $\begin{array}{c}\text { Improvement (\%) } \\
\text { (STC \& PSC) } \\
\text { Respectively }\end{array}$ \\
\hline Searching Time (sec) & 0.08 & 0.06 & 25 \\
Maximum Power Point (W) & $67.82,51.10$ & $69.97,52.26$ & $3.17,2.27$ \\
Relative- error (\%) & $3.11,2.29$ & $0.04,0.08$ & $3.07,2.21$ \\
Tracking Efficiency (\%) & $96.80,97.71$ & $99.96,99.92$ & $3.26,2.26$ \\
\hline
\end{tabular}


Photovoltaic Energy Systems (Vol. 1). Springer Nature Switzerland: Springer.

Geem, Z. W.; J. H. Kim and G. V. Loganathan. (2001). A new heuristic optimization algorithm: harmony search. simulation, 76(2), 60-68.

Jiang, L. L.; D. L. Maskell and J. C. Patra. (2013). A novel ant colony optimization-based maximum power point tracking for photovoltaic systems under partially shaded conditions. Energy and Buildings, 58, 227-236. doi:https://doi.org/10.1016/j.enbuild.2012.12.001

Keerthi, C.; D. L. Lakshmi and K. S. Rafi. (2017). An Optimal Maximum Power Point Tracking using optimization algorithm in PV System. International Journal of Advanced Engineering Research and Science (IJAERS) 4(5), 51-55. doi:10.22161/ijaers/nctet.2017.eee.9

Koad, R. B.; A. F. Zobaa and A. El-Shahat. (2016). A Novel MPPT Algorithm Based on Particle Swarm Optimization for Photovoltaic Systems. IEEE Transactions on Sustainable Energy, 8(2), 468-476. doi:10.1109/TSTE.2016.2606421

Lian, K.; J. Jhang and I Tian. (2014). A maximum power point tracking method based on perturb-and-observe combined with particle swarm optimization. IEEE journal of photovoltaics, 4(2), 626-633. doi:10.1109/JPHOTOV.2013.2297513

Lopez-Santos, O.; G. Garcia; L. Martinez-Salamero; R. Giral; E. Vidal-Idiarte; M. C. Merchan-Riveros and Y. Moreno-Guzman. (2018). Analysis, Design, and Implementation of a Static Conductance-Based MPPT Method. IEEE Transactions on Power Electronics, 34(2), 1960-1979. doi:10.1109/TPEL.2018.2835814

Mahdavi, M.; M. Fesanghary and E.Damangir. (2007). An improved harmony search algorithm for solving optimization problems. Applied Mathematics and Computation, 188(2), 1567-1579. doi:https://doi.org/10.1016/j.amc.2006.11.033

Manjarres, D.; I. Landa-Torres; S. Gil-Lopez; J. Del Ser; M. N. Bilbao; S. Salcedo-Sanz and Z. W. Geem. (2013). A survey on applications of the harmony search algorithm. Engineering Applications of Artificial Intelligence, 26(8), doi:https://doi.org/10.1016/j.engappai.2013.05.008

Mao, M.; Q. Duan; P. Duan and B. Hu. (2018). Comprehensive improvement of artificial fish swarm algorithm for global MPPT in PV system under partial shading conditions. Transactions of the Institute of Measurement Control Engineering Practice, 40(7), 2178-2199. doi:https://doi.org/10.1177/0142331217697374
Mao, M.; L. Zhou; Z. Yang; Q. Zhang; C. Zheng; B. Xie and Y. Wan. (2019). A hybrid intelligent GMPPT algorithm for partial shading PV system. Control Engineering Practice, 83, 108-115. doi:https://doi.org/10.1016/j.conengprac.2018.10.013

Mohapatra, A.; B. Nayak; P. Das and K. B. Mohanty. (2017). A Review on MPPT Techniques of PV System Under Partial Shading Condition. Renewable Sustainable Energy Reviews, 80, 854-867. doi:https://doi.org/10.1016/j.rser.2017.05.083

Ovaska, S. (2010). Maximum Power Point Tracking Algorithms for Photovoltaic Applications. (Masters of Science in Technology), Aalto University Foundations, Finland, Published, 1-82.

Pilakkat, D. and Kanthalakshmi, S. (2019). An improved $\mathrm{P} \& \mathrm{O}$ algorithm integrated with artificial bee colony for photovoltaic systems under partial shading conditions. Solar Energy, 178, 37-47. doi:https://doi.org/10.1016/j.solener.2018.12.008

Saidu, S.; P. U. Okorie; G. A. Olarinoyi; I. O. Momoh and A. Umar. (2019). Modeling and analysis of an improved PV array system under partially shaded conditions. ATBU Journal of Science, Technology Education, 7(4), 191-197.

Shams El-Dein, M. (2012). Novel Designs for Photovoltaic Arrays to Reduce Partial Shading Losses and to Ease Series Arc Fault Detection. (Doctor of Philosophy) Department of Electrical and Computer Engineering,

Waterloo, Ontario, Canada, Published, 100.

Valdez, F.; P. Melin and O. Castillo. (2014). A survey on nature-inspired optimization algorithms with fuzzy logic for dynamic parameter adaptation. Expert systems with applications, 41(14), 6459-6466. doi:https://doi.org/10.1016/j.eswa.2014.04.015

Wei, T.; D. Liu and C. Zhang. (2017). An Improved Particle Swarm Optimization (PSO)-Based MPPT Strategy for PV System. Paper presented at the MATEC Web of Conferences.

Yang, Z.; Q. Duan; J. Zhong; M. Mao and Z. Xun. (2017). Analysis of Improved PSO and Perturb \& Observe Global MPPT Algorithm for PV Array under Partial Shading Condition. Paper presented at the 2017 29th Chinese Control And Decision Conference (CCDC), Chongqing, China.

Zhao, S.-Z.; P. N. Suganthan; Q.-K. Pan and M. F. Tasgetiren. (2011). Dynamic multi-swarm particle swarm optimizer with harmony search. Expert Systems with Applications, 38(4), 3735-3742. 